\title{
Memory is not extinguished along with CS presentation but within a few seconds after CS-offset
}

\author{
Luis María Pérez-Cuesta, Yanil Hepp, María Eugenia Pedreira, and Héctor Maldonado ${ }^{1}$ \\ Laboratorio de Neurobiología de la Memoria, Departamento de Fisiología, Biología Molecular y Celular, IFIBYNE-CONICET, \\ Facultad Ciencias Exactas y Naturales, Universidad de Buenos Aires, Buenos Aires, C1428EHA, Argentina
}

\begin{abstract}
Prior work with the crab's contextual memory model showed that CS-US conditioned animals undergoing an unreinforced CS presentation would either reconsolidate or extinguish the CS-US memory, depending on the length of the reexposure to the CS. Either memory process is only triggered once the CS is terminated. Based on these results, the following questions are raised. First, when is extinction memory acquired, if not along extinction training, and how long does it take? Second, can acquisition and consolidation of extinction memory be pharmacologically dissected? Here we address these questions performing three series of experiments: a first one aimed to study systematically the relationship between extinction and increasing periods of unreinforced CS presentations, a second one to determine the time boundaries of the extinction memory acquisition, and the third one to assay the requirement for protein synthesis and NMDA-like receptors of acquisition and consolidation of extinction memory. Our results confirm that it is CS-offset and not the mere retrieval (CS-onset) that triggers acquisition of extinction memory and that it is completed in less than $45 \mathrm{sec}$ after CS-offset. In addition, protein synthesis is required for consolidation but not for acquisition of this memory and, conversely, NMDA-like receptor activity is required for its acquisition but not for its consolidation. Finally, we offer an interpretative scheme of our results and we discuss to what extent it could apply to multitrial extinction.
\end{abstract}

Prior work of our laboratory with the crab's contextual memory model (Maldonado 2002) showed that CS-US conditioned animals undergoing an unreinforced CS presentation would either reconsolidate or extinguish the CS-US memory, depending on the length of CS presentation. A short presentation $(<1 \mathrm{~h})$ induces reconsolidation whereas a long presentation $(>1 \mathrm{~h})$ induces CS-US extinction, and either process is only triggered once the CS is terminated (Pedreira and Maldonado 2003). During the CS presentation (a re-exposure to the training context) the retrieved CS-US memory remains always intact and consolidated (Pedreira et al. 2004). Supporting this conclusion, impressive early results from our laboratory had shown that the CS-US memory emerges intact when animals are tested before the termination of a 24-hlong unreinforced CS presentation (Lozada et al. 1990).

These previous results led us to propose (1) that the crab's system is able to compute time interval duration, (2) that the outcome of this time computation (i.e., whether it is a short or a long CS presentation) acts as a switch, leading the memory course either to reconsolidation or to extinction, and (3) that CS-US memory is never extinguished synchronously with the unreinforced CS, no matter how long it is. This late suggestion is at odds with the current view that the CS-US memory is gradually extinguished along the unreinforced CS presentations, as observed in multitrial extinction experiments where is shown a progressive CR decrement along the extinction training. (Pavlov 1927; Santini et al. 2001; Haselgrove and Pearce 2003; Lebron et al. 2004).

In the framework of these proposals, we raise the following questions. First, when is extinction memory acquired, if not along extinction training (i.e., the CS presentation), and how long does it take? Second, can acquisition and consolidation of extinction memory be pharmacologically dissected? Since acqui-

\footnotetext{
${ }^{1}$ Corresponding author.
}

E-mail hector@fbmc.fcen.uba.ar; fax 54-11-45763384.

Article is online at http://www.learnmem.org/cgi/doi/10.1101//m.413507. sition of extinction memory depends on a behavioral experience lasting more than $1 \mathrm{~h}$, does it require protein synthesis?

Our model of single-trial extinction appears particularly suitable for studying these issues, since it allows us to determine the precise moment where extinction is disclosed, as a steplike function. Here we address the above questions performing three series of experiments: a first one aimed to study systematically the relationship between extinction and increasing periods of unreinforced CS presentations, a second one aiming to determine the time boundaries of acquisition of the extinction memory, and the third one to assay the requirement for protein synthesis and NMDA-like receptors of acquisition and consolidation of extinction memory. For these purposes, we use the context-signal memory (CSM) model in the crab Chasmagnathus, in which the crab associates the training context (CS) with a visual danger stimulus (VDS, US) passing overhead. After the iterative spaced presentation of the VDS, the initial escape response is replaced by a strong freezing-to-VDS (CR) (Maldonado 2002). This CS-US memory is extinguished after a single unreinforced reexposure to the training context, provided it lasts more than $1 \mathrm{~h}$.

Our results show that extinction memory acquisition is completed in less than $45 \mathrm{sec}$ after CS-offset. In addition, protein synthesis is required for consolidation but not for acquisition of this memory and, conversely, NMDA-like receptors activity is required for its acquisition but not for its consolidation. Finally, we offer an interpretative scheme of our results and we discuss to what extent it could apply to multitrial extinction in this and other species.

\section{Definitions}

As previously pointed out (Myers and Davis 2002; Rescorla 2004), extinction and related terms have been used in literature with different meanings. Therefore, it seems pertinent to define the sense they are given here. Throughout this article, "extinction" refers to the loss or decrement of the CR after unreinforced CS 
presentation. "Acquisition of extinction memory" is understood as the process of acquiring a new memory that controls the behavior. This memory is thus named "extinction memory," as opposed to "CS-US memory" (the crab's CSM that is extinguished). The decrement of the CR (the freezing-to-VDS) measured at some interval after extinction is termed "extinction retention" (or retention of extinction memory).

\section{Results}

\section{Extinction is shown after but not before CS-offset}

The purpose of the present section was to study systematically the relationship between extinction and increasing periods of unreinforced CS presentations, from $5 \mathrm{~min}$ to $6 \mathrm{~h}$, tested either $24 \mathrm{~h}$ after or immediately before CS-offset. This study implies estimating a turning point from which the conditioned response (CR), i.e., the freezing-to-VDS, is no longer displayed. Considering that we are dealing with natural populations that may show some variability for processes occurring in boundary times, experiments around the presumed turning point of CS exposure time were replicated with animals coming from different capture events.

The first series includes four experiments, each having a group of trained crabs and its respective untrained control group. Animals of each experiment come from a same capture event, and different experiments were performed with animals coming from different capture events. During Day 1, the trained group (TR) received the training of 15 trials, whereas the untrained group (UN) acted as control. On Day 2, all the animals were re-exposed to the training context (CS) for 5, 60, 120, or $180 \mathrm{~min}$. At the end of the respective context reexposure, the crabs were moved from the training context to individual rest containers. On Day 3, both trained and untrained crabs received a test trial.

Figure 1A presents the results corresponding to the test trial, normalized with respect to the mean response of the related UN group. Crabs re-exposed to the CS for 5 or $60 \mathrm{~min}$ displayed retention of the CS-US memory, i.e., no extinction (UN $>$ TR, $t$-test $P<0.02$ and $P<0.04$, respectively), whereas those reexposed for 120 or $180 \mathrm{~min}$ evinced extinction retention (UN $\sim$ TR, $P=0.88$ and $P=0.85$, respectively). The two replications of each experiment around the turning point (not shown) confirmed the results for $5 \mathrm{~min}(\mathrm{UN}>\mathrm{TR}, P<0.01$ and $P<0.03)$ and $120 \mathrm{~min}(\mathrm{UN} \sim \mathrm{TR}, P=0.56$ and $P=0.75)$, but for $60 \mathrm{~min}$, one replication again showed CS-US memory retention (UN $>$ TR, $P<0.02$ ) while the other one showed extinction retention ( $\mathrm{UN} \sim \mathrm{TR}, P=0.55)$. Thus, the turning point from which the $\mathrm{CR}$ is no longer displayed may be estimated around $60 \mathrm{~min}$.

The second series includes five experiments with the same protocols as above in all respects, but the animals were tested on Day 2 immediately before removal from the training context (i.e., before CS-offset) instead of $24 \mathrm{~h}$ later. Figure 1B shows results corresponding to the test trial. No extinction was disclosed in any case, i.e., significant UN-TR differences were found for every CS re-exposure time (UN $>$ TR; $P<0.0001$ for $5 \mathrm{~min}$; $P<0.007$ for $60 \mathrm{~min} ; P<0.0001$ for $120 \mathrm{~min} ; P<0.0004$ for 180 min; $P<0.009$ for $360 \mathrm{~min})$. Experiments around the estimated boundary of re-exposure time were replicated once (not shown) and results were confirmed in every case (UN $>$ TR; $P<0.0008$ for $5 \mathrm{~min} ; P<0.002$ for $60 \mathrm{~min} ; P<0.003$ for $120 \mathrm{~min}$ ). This failure to show extinction, despite a long CS re-exposure without reinforcement, is in keeping with previous experiments in our laboratory, where CS-US memory retention appeared intact after 12 or $24 \mathrm{~h}$ of unreinforced CS re-exposure when tested before CSoffset (Lozada et al. 1990; Tomsic et al. 1998).

In short, the pattern of results obtained by testing extinction $24 \mathrm{~h}$ after CS-offset, is markedly different from that obtained by testing it immediately before CS-offset. The former reveals extinction retention with the progressive lengthening of the reexposure time; the latter, no extinction at any time point of the re-exposure. These findings support the view that acquisition of the new memory (the extinction memory) depends on both the duration of the unreinforced CS re-exposure and the occurrence of the CS-offset.

\section{Extinction memory acquisition is completed in a period not longer than $45 \mathrm{sec}$ after CS-offset}

The above results are interpreted in keeping with the idea that acquisition of extinction memory only takes place once the CS is terminated, since this would be the key point where the extinction-reconsolidation switch would operate according to the previous re-exposure time (Pedreira and Maldonado 2003). Consequently, the purpose of the following series of experiments was to point out the temporal boundaries of the extinction memory
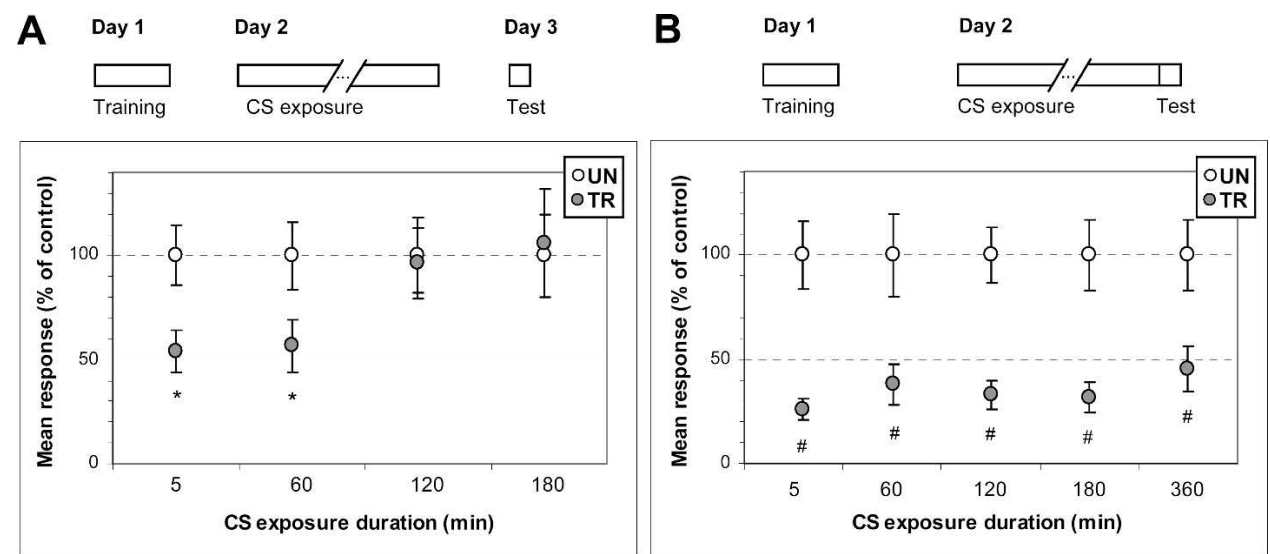

Figure 1. Extinction memory requires both an unreinforced CS re-exposure longer than $1 \mathrm{~h}$ and CS termination. ( $A$, upper diagram) Experimental protocol. Open boxes stand for time periods of training, treatment, and test sessions. Crabs were trained on Day 1, re-exposed on Day 2 to the training context (CS) for 5, 60, 120, or 180 min, and tested on Day 3. (Lower panel) Mean responses at test on Day 3, normalized with respect to the mean response of the UN group. White circles stand for untrained (UN) groups, gray circles for trained (TR) groups. Bars stand for S.E.M. * $P<0.05$. (B, Upper diagram) Experimental protocol. Crabs were trained on Day 1, re-exposed on Day 2 to the training context for 5, 60, 120, 180, or 360 min, and tested on Day 2, before CS-offset. (Lower panel) Mean responses and S.E.M. at test, normalized with respect to the UN group. \#P<0.01. Symbols and indications as $A$.

\section{Learning \& Memory}

www.learnmem.org 
acquisition, by reducing progressively the time interval between CS-offset (i.e., the crab's removal from the training context) and the later test trial. Previously, extinction had been shown at a test trial given $2 \mathrm{~h}$ after CS-offset (Pedreira et al. 2004) or even only 5 min after (preliminary results, data not shown). However, when we attempted to test periods shorter than $5 \mathrm{~min}$, we came up against a difficulty. Removal of the crab from the training context followed by moving it back after such a short time entails a maneuver of repeated handling, which affects the behavior about to be tested, making results inconsistent. To overcome this drawback, we searched for a method that allows us to mark the CSoffset without removing the animal, specifically, by only changing the illumination of the training context from above to below. We assumed that the effect of this light shift on the extinction memory acquisition would be equivalent to that of the CS-offset marked by the crab's removal. For testing this equivalence, the following experiment with two pairs of UN-TR groups was carried out (Fig. 2). One pair of UN-TR groups was re-exposed for 2 $\mathrm{h}$ to the unreinforced CS, then moved for $5 \mathrm{~min}$ to individual cylinders, and then moved back to the training context where the test trial was given. Instead, the other UN-TR pair received the same 2-h CS re-exposure, but this was then followed by $5 \mathrm{~min}$ with light from below and finally the test trial with the usual light from above. Results showed extinction for both the former and the latter pairs of UN-TR groups (UN TR, ANOVA: no main effect, $F_{(3,148)}=171.84, P=0.34 ; P=0.23$, and $P=0.19$, respectively). Thus, the effect of the light shift for 5 min was similar to that of removing the crab and keeping it for $5 \mathrm{~min}$ in an isolated container. Namely, the crab seems to take both removal from the training context and light shift as tantamount to the end of the long CS re-exposure. To control the possibility that the loss of CR shown after an interval with light from below was an unspecific effect of the sudden light shift that marks the CS-offset, a further experiment was performed (Fig. 3). During Day 2, $24 \mathrm{~h}$ after the

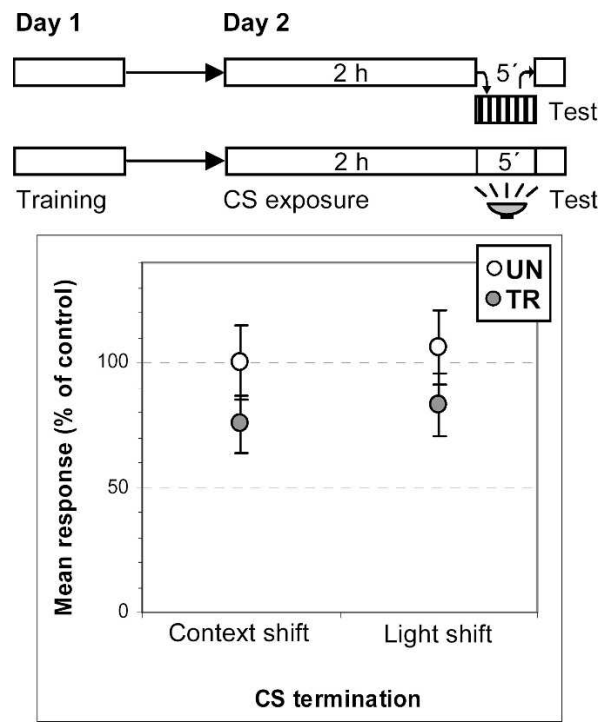

Figure 2. Short term extinction is shown after either 5 min in a different context or 5 min with a different illumination. (Upper diagram) Experimental protocol of two pairs of UN-TR groups. Crabs were trained on Day 1 and re-exposed to the training context for $2 \mathrm{~h}$ on Day 2 . In one pair of UN-TR groups, first line, CS-offset is denoted by removal of the crab, followed by its placement for 5 min in a different context (striped box). In the other UN-TR pair, second line, CS-offset is denoted by changing illumination from above to below for 5 min (lamp sign). All crabs received the test trial in the training context with the usual illumination from above. (Lower panel) Mean responses and S.E.M. at test, normalized with respect to the UN group. Other symbols and indications as in Figure 1.

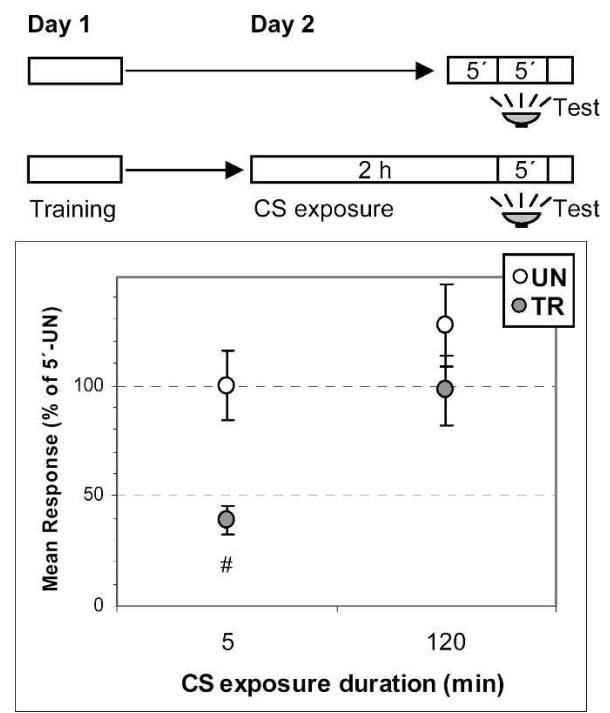

Figure 3. Loss of conditioned response after illumination shift depends on extinction training and not on illumination shift itself. (Upper diagram) Experimental protocol. Crabs were trained on Day 1 and re-exposed to the training context on Day 2 for 5 min (first pair of UN-TR groups) or for $2 \mathrm{~h}$ (second UN-TR pair). Next, illumination was shifted from above to below for 5 min in both pairs of UN-TR groups. Right after, illumination was restored and crabs were tested with light from above. (Lower panel) Mean responses and S.E.M. at test, normalized with respect to the UN group of first pair. Other symbols and indications as in Figure 1.

training session, UN-TR groups of crabs were CS re-exposed without reinforcement either for $2 \mathrm{~h}$ or for only $5 \mathrm{~min}$. Next, the context illumination was shifted for all crabs to light from below for $5 \mathrm{~min}$, then shifted back to light from above, and all crabs received a test trial. As expected, the 2 -h UN-TR pair showed extinction while the 5-min UN-TR pair exhibited an intact conditioned response (ANOVA: main effect $F_{(3,150)}=6.46$, $P<0.0004 ; P=0.16$ for the 2 -h pair, $P<0.003$ for the 5 -min pair). Thus, an explanation in terms of unspecific effects of the light shift can be ruled out.

Based on this method, we tried to determine how long is needed between CS-offset and test trial to acquire the extinction memory. The protocol was as that shown above in Figure 1, but here the test trial was given immediately before $(0 \mathrm{sec})$ or 9,27 , $45,63,240$, or $300 \mathrm{sec}$ after CS-offset, with illumination from below during the interval between CS-offset and test trial. Figure 4 presents results at test trial. When crabs were tested before CS-offset $(0 \mathrm{sec})$, no extinction was revealed, i.e., there were significant $\mathrm{UN}-\mathrm{TR}$ differences $(\mathrm{UN}>\mathrm{TR}, P<0.002$ ). The same result was found for crabs tested $9 \mathrm{sec}$ and $27 \mathrm{sec}$ after CS-offset (UN $>$ TR, $P<0.01$ and $P<0.02$, respectively); but when tested at $45,63,240$, or $300 \mathrm{sec}$, all of them exhibited extinction (UN $\sim \mathrm{TR}$, $P=0.32, P=0.84, P=0.27$, and $P=0.23$, respectively). Again, since this study entails estimating turning points, experiments around the presumed boundary time of CS exposure were replicated twice (not shown). Results were confirmed at every time point, excepting one of the two replications at $27 \mathrm{sec}$, where extinction was shown instead of CS-US retention (UN $>$ TR, $P<0.002$ and $P<0.008$ for 0 sec; $\mathrm{UN}>\mathrm{TR}, P<0.03$ and $P<0.03$ for $9 \mathrm{sec}$; UN $>$ TR, $P<0.0006$ and $\mathrm{UN} \sim \mathrm{TR}, P=0.16$ for $27 \mathrm{sec}$; $\mathrm{UN} \sim \mathrm{TR}, P=0.23$ and $P=0.96$ for $45 \mathrm{sec}$ ). Thus, the turning point from which the extinction memory appears to be completed may be estimated as less than $45 \mathrm{sec}$ after CS-offset.

However, other alternative or complementary explanations may be offered. It could be argued that this period of $45 \mathrm{sec}$ entirely with light from below is the shortest time interval nec- 


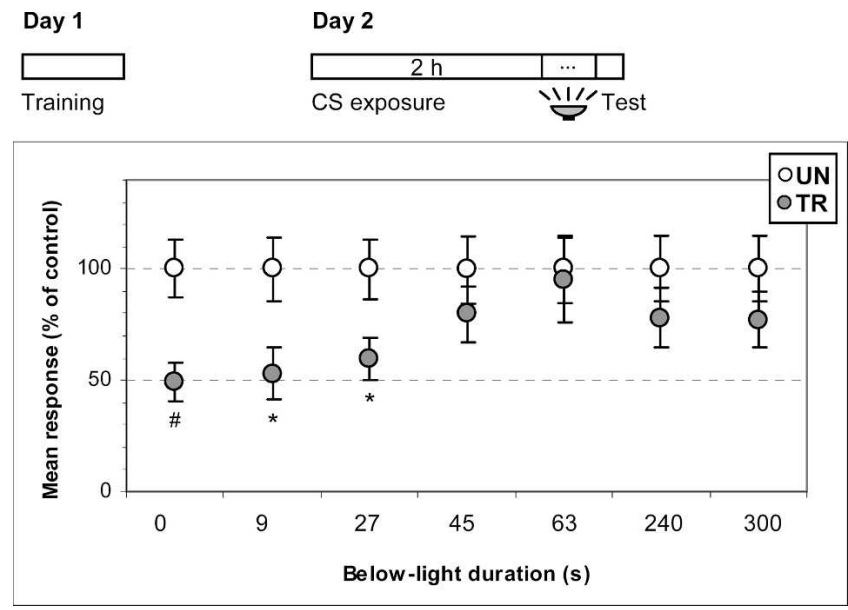

Figure 4. Not more than $45 \mathrm{sec}$ after $\mathrm{CS}$ termination are required to acquire extinction memory. (Upper diagram) Experimental protocol. Crabs were trained on Day 1 and re-exposed on Day 2 to the training context for $2 \mathrm{~h}$. The CS-offset is denoted by an above-to-below shift of illumination. The test trial was given immediately before CS-offset $(0 \mathrm{sec})$ or after a period ranging from $9 \mathrm{sec}$ to $5 \mathrm{~min}$ with illumination from below. Test trials with light from above. (Lower panel) Mean responses and S.E.M. at test, normalized with respect to the UN group. Other symbols and indications as in Figure 1.

essary for the animal to take the illumination shift as equivalent to the CS-offset, rather than a time for completing the extinction memory acquisition. A further experiment was carried out to address this question (Fig. 5). After the 2-h CS presentation without reinforcement, one pair of UN-TR groups had $9 \mathrm{sec}$ of light from below, followed by the test trial, while the other UN-TR pair had the same 9 sec of light from below but followed by 36 sec of light from above and then the test trial. Results revealed that crabs with light from below for 9 sec failed to show extinction while those with an additional $36 \mathrm{sec}$ with light from above did extinguish CS-US memory (ANOVA: main effect, $F_{(3,156)}=3.73$, $P<0.02 ; \mathrm{UN}>\mathrm{TR}, P<0.005$ and $\mathrm{UN} \sim \mathrm{TR}, P=0.28$, respectively). Therefore, 9 sec of light from below is not long enough for the

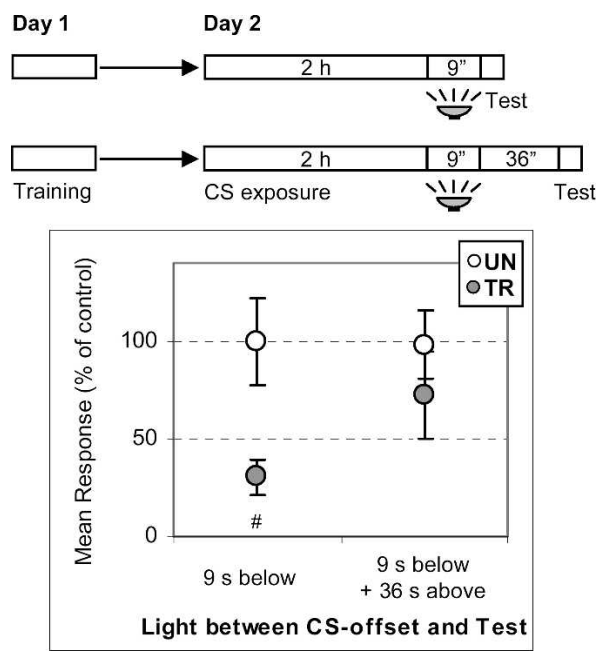

Figure 5. Nine seconds with light from below are enough for the animal to detect the CS-offset. (Upper diagram) Crabs were trained on Day 1 and re-exposed to the training context for $2 \mathrm{~h}$ on Day 2. Before test trial, crabs underwent a period of either $9 \mathrm{sec}$ with light from below (first pair) or $9 \mathrm{sec}$ with light from below plus $36 \mathrm{sec}$ with light from above (second pair). Test trials with light from above. (Lower panel) Mean responses and S.E.M. at test, normalized with respect to the UN group. Other symbols and indications as in Figure 1. animal to acquire the extinction memory, but it is to mark the end of the previous CS re-exposure, since the second UN-TR pair with the same $9 \mathrm{sec}$ of light from below but an additional $36 \mathrm{sec}$ from above shows extinction. In conclusion, the time required to detect the CS-offset appears shorter ( $\leq 9 \mathrm{sec}$ with light from below) than that necessary to acquire the extinction memory ( $\leq 45 \mathrm{sec}$ ).

\section{Protein synthesis subserves consolidation but not acquisition of the extinction memory}

The following series of experiments was performed to determine whether de novo protein synthesis is required for extinction memory acquisition. Considering the extremely brief time period estimated for extinction memory acquisition, the requirement of protein synthesis seems untenable, although it could be necessary during the previous $2 \mathrm{~h}$ of CS re-exposure.

Prior experiments in our laboratory demonstrated that $15 \mu \mathrm{g}$ per crab of cycloheximide (CHX), given between 0 and $4 \mathrm{~h}$ after training, impairs consolidation of CS-US memory tested at $24 \mathrm{~h}$ (Pedreira et al. 1995, 1996). Here, we intend to test whether protein synthesis is required for acquisition of extinction memory, using an experimental design similar to that of the previous experiments: namely, training session on Day 1, CS re-exposure for $2 \mathrm{~h}$ on Day 2, with CHX or saline (SAL) injections before the CS re-exposure. Crabs were tested either immediately before CSoffset or $5 \mathrm{~min}$ or $24 \mathrm{~h}$ after CS-offset. Results indicate that both SAL- and CHX-injected crabs displayed intact conditioned response when tested before CS-offset (Fig. 6A) (UN > TR; ANOVA: significant main effect $F_{(3,116)}=3.31, P<0.02 ; P<0.03$ for SAL and $P<0.03$ for $\mathrm{CHX}$ ), and both displayed extinction when tested 5 min after CS-offset (Fig. 6B) (UN TR; ANOVA: no main effect $F_{(3,153)}=0.5, P=0.68 ; P=0.7$ for SAL and $P=0.44$ for $\mathrm{CHX}$ ). Thus, CHX failed to block both the CS-US memory retrieval (Fig. 6A) and extinction memory acquisition (Fig. 6B). Instead, if tested $24 \mathrm{~h}$ later (Fig. 6C), SAL-injected crabs showed extinction memory while $\mathrm{CHX}$-injected crabs displayed intact CS-US memory (ANOVA: main effect $F_{(3,152)}=3.40, P<0.02$; $\mathrm{UN} \sim \mathrm{TR}$ for SAL, $P=0.51$ and $\mathrm{UN}>\mathrm{TR}$ for $\mathrm{CHX}, P<0.003)$. This result suggests that $\mathrm{CHX}$ injected before $\mathrm{CS}$ re-exposure persisted beyond the time interval required for extinction memory acquisition and succeeded in blocking extinction memory consolidation. This is in agreement with prior results (Pedreira et al. 2004) showing that an injection of CHX given $2 \mathrm{~h}$ after CS-offset impairs consolidation of extinction memory. Therefore, protein synthesis is not required either for acquiring extinction memory, a process that is accomplished in a few seconds, or during the previous $2 \mathrm{~h}$ of CS re-exposure. Instead, protein synthesis is required for consolidation of the extinction memory.

\section{Activity of NMDA-like receptors is required for} acquisition but not consolidation of extinction memory Prior experiments in our laboratory showed that an injection of $1 \mu \mathrm{g} / \mathrm{g}$ of MK-801, the vertebrate noncompetitive antagonist of NMDA receptors, disrupts the crab's CS-US memory consolidation (Troncoso and Maldonado 2002) and reconsolidation (Pedreira et al. 2002). Instead, it has no effect on CS-US memory acquisition nor on its retrieval (Troncoso and Maldonado 2002). These findings suggested a role for NMDA-like receptors in the storage of long-term memory in the crab. In addition, the occurrence of these receptors in crustaceans has been often reported (Pfeiffer-Lynn and Glantz 1991; Parnas et al. 1996; Burgess and Derby 1997; Schramm and Dudel 1997; Feinstein et al. 1998). Here, the first experiments in this series were aimed at testing the effect of MK-801 on acquisition and consolidation of the extinction memory. For this purpose, crabs were injected before the 2-h unreinforced CS re-exposure, with MK-801 (1 $\mu \mathrm{g} / \mathrm{g})$ or SAL. All the crabs received a test trial, either $5 \mathrm{~min}$ or $24 \mathrm{~h}$ after CS-offset
104 Learning \& Memory

www.learnmem.org 
A

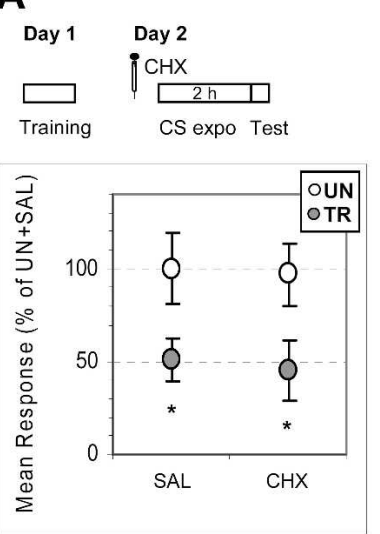

B

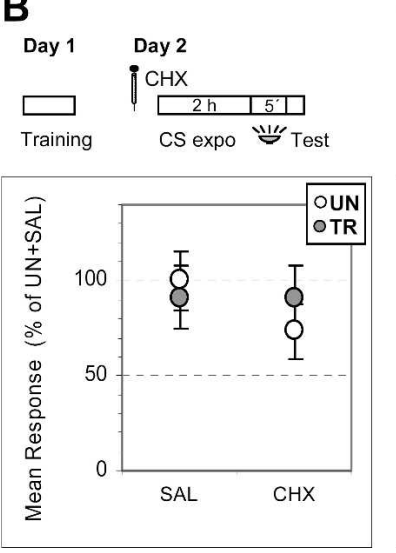

C

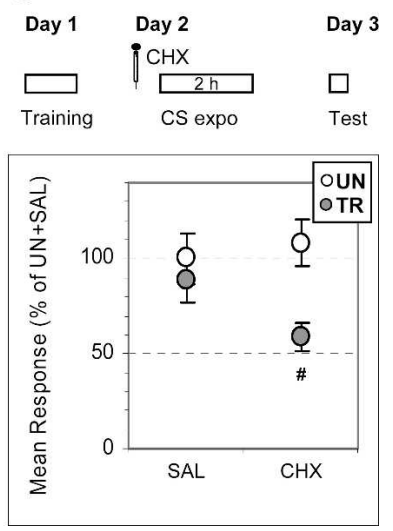

Figure 6. Cycloheximide has no effect either on CS-US retrieval or on acquisition of CS-US extinction, but impairs extinction consolidation. (Upper diagrams) Crabs were trained on Day 1, injected on Day 2 with saline (SAL) or cycloheximide (CHX), and then re-exposed to the training context for $2 \mathrm{~h}$. Test trial with light from above either $(A)$ before CS-offset, $(B)$ after 5 min with light from below, or $(C)$ on Day 3. (Lower panels, $A-C$ ) Mean responses and S.E.M. at test, normalized with respect to the UN group of the SAL pair of each experiment. Other symbols and indications as in Figure 1.

(Fig. 7A,B, respectively). When tested 5 min after CS-offset, crabs injected with SAL showed extinction while those injected with MK-801 disclosed intact CS-US memory (Fig. 7A) (ANOVA: main effect, $F_{(3,148)}=2.74, P<0.04 ; \mathrm{UN} \sim \mathrm{TR}$ for SAL, $P=0.16$ and $\mathrm{UN}>\mathrm{TR}$ for MK-801, $P<0.01)$. Similar results were obtained when crabs were tested $24 \mathrm{~h}$ after CS-offset (Fig. 7B) (ANOVA: main effect, $F_{(3,116)}=6.58, P<0.0004 ; \mathrm{UN} \sim$ TR for SAL, $P=0.31$ and UN $>$ TR for MK-801, $P<0.001)$. Since MK-801 injections were given before CS re-exposure, present results suggest that NMDA-related receptors are required either only for acquisition or both for acquisition and consolidation of extinction memory. To distinguish between these two possibilities, in the next experiments crabs were injected with SAL or MK-801 either $5 \mathrm{~min}$, $30 \mathrm{~min}$, or $1 \mathrm{~h}$ after CS-offset, and tested $24 \mathrm{~h}$ later (Fig. 7C). Extinction memory was observed for both SAL- and MK-801injected crabs, for all three times of injection. (For 5-min injection, ANOVA: no main effect, $F_{(3,116)}=0.47, P=0.7 ; P=0.66$ and $P=0.37$ for SAL and MK-801, respectively. For $30 \mathrm{~min}$ injection, ANOVA: no main effect, $F_{(3,155)}=0.77, P=0.51$; $P=0.77$ and $P=0.35$ for SAL and MK801. For $1 \mathrm{~h}$ injection, ANOVA: no main effect, $F_{(3,152)}=0.59, P=0.62 ; P=0.54$ and $P=0.32$ for SAL and MK-801). In conclusion, MK-801 injections, given before CS re-exposure, impair acquisition of extinction memory but they have no effect on extinction memory consolidation. This result is wholly inverse to those previously reported on acquisition and consolidation of the crab's CS-US memory (Troncoso and Maldonado 2002).

\section{Discussion}

Results of this article confirm and substantially extend previous ones, supporting our hypothesis relative to the necessary requirements for acquiring extinction memory as well as to the kinetics of this acquisition (Pedreira and Maldonado 2003; Pedreira et al. 2004). indications as in Figure 1.
A

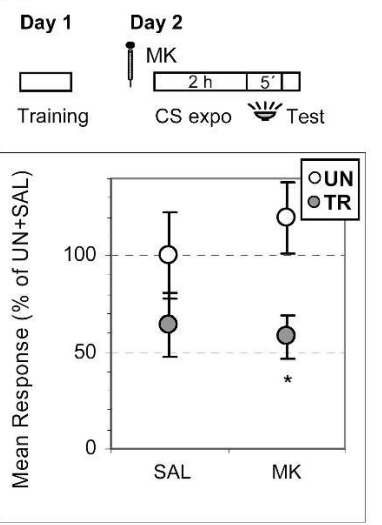

B

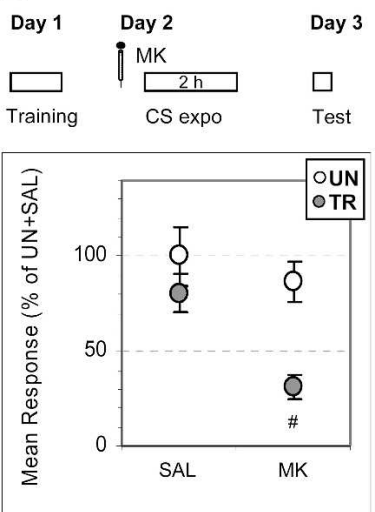

C
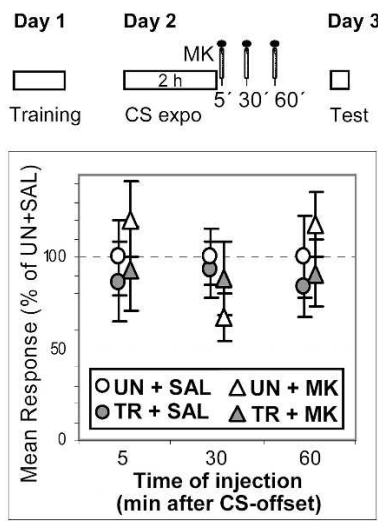

Figure 7. MK-801 impairs extinction acquisition but has no effect on extinction consolidation. (Upper diagrams) $(A, B)$ Crabs were trained on Day 1 and injected on Day 2 with saline (SAL) or MK-801 (MK) before being re-exposed for $2 \mathrm{~h}$ to the training context. Test trial with light from above either $(A)$ after a 5-min above-to-below light shift, $(B)$ on Day 3. (C) Crabs were trained on Day 1, re-exposed on Day 2 to the training context for $2 \mathrm{~h}$ and injected with saline (SAL) or MK-801 (MK) 5, 30, or 60 min later. Test trial with light from above on Day 3. (Lower panel, $A, B, C$ ) Mean responses and S.E.M. at test, normalized with respect to the UN group of the SAL pair of each experiment. Other symbols and 
animal's system is not acquiring any information related to the future extinction memory. In fact, since the outcome of the experience depends on the CS duration, we can at least infer time is being computed. Therefore, if extinction is only triggered after CS-offset, there is no other functional requirement to take place during CS re-exposure. Hence, we hypothesize that the entire period of CS re-exposure is an "expectation time," where the animal computes time up to CS-offset without triggering either memory process. Once the CS-offset comes, extinction is triggered, provided the expectation time lasted $>1 \mathrm{~h}$ and no US was presented.

\section{Extinction memory acquisition is completed in less than $45 \mathrm{sec}$ after CS-offset}

Results have shown that after $2 \mathrm{~h}$ of unreinforced CS re-exposure the same VDS retrieves either the CS-US memory, if presented just before CS-offset, or the extinction memory, if presented at least $45 \mathrm{sec}$ after CS-offset (Fig. 4). Therefore, the extinction memory is acquired in a remarkably short period of time. This is the first time that extinction memory acquisition has been so sharply dissected in time. In addition, this acquisition period is noncontemporaneous with CS re-exposure, a finding at variance with the current view that extinction memory is acquired at the same time as CS re-exposure.

It is worth noting that this 45 -sec interval is the time span required to acquire the new extinction memory, regardless of the context features that follow the CS-offset (Fig. 5).

\section{Pharmacological dissection of acquisition and consolidation of extinction memory}

We found that MK-801-sensitive putative NMDA receptors are required for acquisition but not for consolidation of the crab's extinction memory (Fig. 7). These results are in keeping with those obtained in rodents, showing that NMDA receptor activation is critical for acquiring the extinction memory, either when the antagonist is given systemically (Baker and Azorlosa 1996) or directly into the amygdala (Lin et al. 2003) or into the hippocampus (Szapiro et al. 2003). Our results also agree with other studies showing no effect of NMDA receptor antagonists when administered immediately after extinction training (Akirav et al. 2006).

Conversely, protein synthesis is required for consolidation but not for acquisition of extinction memory (Fig. 6). This means that de novo protein synthesis is not necessary, either for the mechanisms engaged in acquiring extinction or for the previous time computation during the expectation time. Similar results were obtained in previous experiments with rodents (Santini et al. 2001; Suzuki et al. 2004).

In short, behavioral and pharmacological results support our hypothesis that extinction memory acquisition does not occur during the CS presentation but instead, is induced in a few seconds upon CS-offset. However, it would be possible that plastic changes had already occurred at the time of CS-offset and that expression of extinction memory is what is triggered. A pharmacological tool may be used to decide between these possibilities, namely, a further injection of MK-801 given just prior to the offset of the CS presentation. If extinction memory were already acquired at the time of CS-offset, then MK-801 would have no effect, whereas if extinction memory acquisition truly does occur very rapidly upon CS-offset, then MK-801 would block this process. A requirement for this experiment is to design a technique that allows for injection of the drug without the removal of the crab from the context, since removal implies CS-offset.

\section{General validity of our interpretative scheme}

At this point, we must address two questions regarding the general validity of the above interpretative scheme. First, to what extent is this scheme, proposed for the case of one-trial extinction in crabs, applicable to other animals? And second, to what extent does it cover the case of multitrial extinction?

In attempting to answer the first question we come up against two difficulties. There are few instances of experiments of one-trial extinction available in the literature, and in addition, the level of extinction during the CS re-exposure is assessed by using an inappropriate method for this purpose. Recently, Cain et al. (2003) and Suzuki et al. (2004) showed, in a contextual fear paradigm with mice, that a 10- or 30-min trial of continuous CS re-exposure discloses freezing decline with the increasing CS presentation. That is, the progress of extinction would occur gradually along the CS re-exposure, a conclusion totally in conflict with our results. However, although freezing for a short test trial may be a good measure of the CR level, it appears unsuitable for a long and continuous test trial. In fact, a decrease in freezing could be the expression of a reduction in fear, but it might also be accounted for by habituation and/or fatigue, as has been extensively discussed by various authors (McSweeney and Swindell 2002) including Cain et al. (2003, 2004). Instead, when measuring CS-US extinction in the crab, it is possible to conclude reliably that no extinction occurred during CS re-exposure, because the CR level is not expressed directly and continuously as constant freezing, but disclosed each time from the brief presentation of the VDS in the fear context.

The second point to address is to what extent our interpretative scheme, proposed for the case of one-trial extinction in the crab, may also cover the case of multitrial extinction. We propose that each trial in the series of a multitrial experiment should have all the essential features we described for the one-trial experiment. On the basis of this proposal, we hypothesize that in a series of successive trials, the time computation for each trial includes not only its own expectation time but also those of prior trials. When the accumulation of expectation times surpasses a certain threshold, the CS-offset triggers the acquisition of the extinction memory. In contrast, each previous CS-offset only triggers reconsolidation. A series of experiments in our laboratory is being aimed at testing this hypothesis (Y. Hepp, pers. comm.).

The above results and the hypothesis from our work with crabs have been compared with those from reports on rodents, i.e., a comparison of species phylogenetically far apart. Behind this endeavor is the idea that in the realm of studies on memory, some principles of behavior organization and basic mechanisms at cellular and molecular levels have universal validity (Carew 2000; Pedreira and Maldonado 2003).

\section{Materials and Methods}

\section{Animals}

Animals were adult male crabs (Chasmagnathus granulatus) 2.7$3.0 \mathrm{~cm}$ across the carapace, weighing around $17.0 \mathrm{~g}$, collected from water less than $1 \mathrm{~m}$ deep in the rías (narrow coastal inlets) of San Clemente del Tuyú, Argentina, and transported to the laboratory, where they were lodged in plastic tanks $(35 \times 48 \times 27 \mathrm{~cm})$ filled to $2 \mathrm{~cm}$ depth with diluted marine water, to a density of 20 crabs per tank. Water used in tanks and other containers during experiments was prepared using hwMarinex (Winex-Germany), salinity 10-14\%o, pH 7.4-7.6, and maintained within a range of $22-24^{\circ} \mathrm{C}$. The holding and experimental rooms were maintained on a 12-h light/12-h dark cycle (light on 07:00-19:00 h). Animals were fed rabbit pellets (Nutrientes S.A.) every $3 \mathrm{~d}$ and after feeding the water was changed. Experiments were carried out within $10 \mathrm{~d}$ after the animal's arrival, from January to August, and between 08:00 and 18:00 h. 
Each crab was used in only one experiment. Experimental procedures are in compliance with the policies on the use of Animals and Humans in Neuroscience Research.

\section{The experimental device}

This device (Maldonado 2002), referred to as the training context, consists of a bowl-shaped opaque container with a steep concave wall $12 \mathrm{~cm}$ high $(23 \mathrm{~cm}$ top diameter and $9 \mathrm{~cm}$ floor diameter) covered to a depth of $0.5 \mathrm{~cm}$ with artificial sea water, where the crab was lodged before each experiment. During each trial of $9 \mathrm{sec}$, an opaque rectangular screen $(25 \times 7.5 \mathrm{~cm})$, termed the visual danger stimulus (VDS), was moved horizontally over the animal, cyclically from left to right and vice versa, at a constant speed. The VDS provoked an escape response of the crab and consequent container vibrations, converted into electrical signals through a piezoelectric transducer placed on the external wall of the container. These signals were amplified, integrated during each 9-sec trial, and translated into arbitrary numerical units ranging from 0 to 6000 , before being processed by computer. The activity of every crab was recorded during each entire trial time. The experimental room had 40 devices, separated from each other by partitions. During the experiments, crabs were illuminated with a $5 \mathrm{~W}$ bulb, either from above or from below the training context.

\section{Escape response and freezing}

The amount of container vibrations during the 9 sec of VDS presentation (a trial) depends on the magnitude of the defensive responses the crab displays when faced with an impending threat. Two types of defensive responses are distinguished: namely, escape and freezing responses (Pereyra et al. 1999, 2000). The escape response is a directional run of the animal in an attempt to move away from the passing screen (VDS), while the freezing response consists of a rigid motionless display in which the crab lies flattened on the substratum. During repeated VDS presentations (training), the escape response decreases in intensity and is replaced by the progressive building up of a strong and long-lasting freezing. No defensive responses but exploration or wandering are shown during context exposures without VDS presentation. Throughout this article, data are only recorded during a trial time, i.e., during the 9-sec VDS. No spontaneous activity during context exposures was recorded.

\section{Experimental procedure and design}

Each experiment lasted 2 or $3 \mathrm{~d}$ and included three sessions, namely, training session (on Day 1), treatment session (on Day 2 ), and test session (either on Day 2, right after treatment session, or $24 \mathrm{~h}$ later on Day 3). Untrained (UN) or trained (TR) groups of 30-40 crabs each were formed in each experiment.

\section{Day 1, training session}

Untrained animals (UN) were kept in the training context (CS) during the entire training session ( $\sim 50 \mathrm{~min})$ as controls, i.e., without being presented the visual danger stimulus (VDS = US), and trained animals (TR), after being $5 \mathrm{~min}$ in the container without VDS, received 15 training trials, each consisting of a 9-sec VDS presentation (US), separated by intertrial intervals of $3 \mathrm{~min}$. Immediately after the training session, both UN and TR crabs were moved from the training context to be housed individually in the resting containers, i.e., plastic boxes covered to a depth of 0.5 $\mathrm{cm}$ with water and kept inside dimly lit drawers.

\section{Day 2, treatment session}

Crabs were re-exposed to the training context (CS) for $5 \mathrm{~min}, 1 \mathrm{~h}$, $2 \mathrm{~h}, 3 \mathrm{~h}$, or $6 \mathrm{~h}$, without VDS (US) presentation. In some experiments, an injection of saline (SAL), cycloheximide (CHX), or MK801 (MK) was given 30 min before training context re-exposure. Re-exposure was terminated by (1) removing crabs from the training context, or (2) shifting illumination from above (usual illumination during training and test) to below, provoking thus a virtual change in the environmental features.
After treatment, crabs were returned to the resting containers.

\section{Test trial}

The test trial consisted of one 9-sec VDS trial (US) with the illumination from above in the training context. It was given on Day 2 , either before or after the end of the CS re-exposure, or on Day $3,24 \mathrm{~h}$ after the CS re-exposure.

\section{Drugs and injection procedure}

Crustacean saline solution (Hoeger and Florey 1989) was used as vehicle. Fifty microliters of saline, cycloheximide (15 $\mu \mathrm{g}$ per crab), or MK-801 (17 $\mu \mathrm{g}$ per crab) solution were given through the right side of the dorsal cephalothoraxic-abdominal membrane, by means of a syringe fitted with a sleeve to control depth of penetration to $4 \mathrm{~mm}$, thus ensuring that the injected solution was released in the pericardial sac. Cycloheximide and MK-801 were purchased from Sigma Co.

\section{Data analysis}

Data analysis in this article is aimed at testing a basic prediction drawn from our extensive work on the crab's context-signal memory (CSM). Animals given 15 or more training trials with 3 min of intertrial interval (trained crabs, TR) show, at a test trial, a level of escape response noticeably lower than that of animals that remained in the training context but without being trained (untrained crabs, UN). A statistically significant UN-TR difference $(P<0.05)$ is invariably found, even when crabs were pre- or post-training saline injected. Therefore, a trained group is said to show context-signal memory retention when the basic assumption is confirmed. Based on the UN $>$ TR prediction, data are analyzed using a priori planned comparisons following a significant main effect in a one-way ANOVA $(\alpha<0.05)$ (Rosenthal and Rosnow 1985; Howell 1987). A one-way ANOVA was performed on data corresponding to groups of crabs coming from a same capture event.

\section{Acknowledgments}

This work was supported by FONCYT (grant PICT-R 00349) and by University of Buenos Aires (grant X326). We thank Alejandro Delorenzi and Arturo Romano for reading the manuscript and for helpful criticisms.

\section{References}

Akirav, I., Khatsrinov, V., Vouimba, R.M., Merhav, M., Ferreira, G., Rosenblum, K., and Maroun, M. 2006. Extinction of conditioned taste aversion depends on functional protein synthesis but not on NMDA receptor activation in the ventro medial prefrontal cortex. Learn. Mem. 13: 254-258.

Baker, J.D. and Azorlosa, J.L. 1996. The NMDA antagonist MK-801 blocks the extinction of Pavlovian fear conditioning. Behav. Neurosci. 110: $618-620$.

Burgess, M.F. and Derby, C.D. 1997. Two novel types of L-glutamate receptors with affinities for NMDA and L-cysteine in the olfactory organ of the Caribbean spiny lobster Panulirus argus. Brain Res. 771: 292-304.

Cain, C.K., Blouin, A.M., and Barad, M. 2003. Temporally massed CS presentations generate more fear extinction than spaced presentations. J. Exp. Psychol. Anim. Behav. Process. 29: 323-333.

Cain, C.K., Blouin, A.M., and Barad, M. 2004. Adrenergic transmission facilitates extinction of conditional fear in mice. Learn. Mem. 11: $179-187$.

Carew, T.J. 2000. Behavioral neurobiology: The cellular organization of natural behavior. Sinauer, Sunderland, MA.

Eisenberg, M., Kobilo, T., Berman, D.E., and Dudai, Y. 2003. Stability of retrieved memory: Inverse correlation with trace dominance. Science 301: 1102-1104.

Feinstein, N., Parnas, D., Parnas, H., Dudel, J., and Parnas, I. 1998. Functional and immunocytochemical identification of glutamate autoreceptors of an NMDA type in crayfish neuromuscular junction. J. Neurophysiol. 80: 2893-2899.

Haselgrove, M. and Pearce, J.M. 2003. Facilitation of extinction by an increase or a decrease in trial duration. J. Exp. Psychol. Anim. Behav. Process. 29: 153-166. 
Hoeger, R. and Florey, E. 1989. Catecholamine degradation in the hemolymph of the Chinese crab, Eriocheir sinesis. Comp. Biochem. Physiol. 92C: 323-327.

Howell, D.C. 1987. Statistical methods for psychology. Duxbury, Boston.

Lebron, K., Milad, M.R., and Quirk, G.J. 2004. Delayed recall of fear extinction in rats with lesions of ventral medial prefrontal cortex. Learn. Mem. 11: 544-548.

Lin, C.H., Yeh, S.H., Lu, H.Y., and Gean, P.W. 2003. The similarities and diversities of signal pathways leading to consolidation of conditioning and consolidation of extinction of fear memory. $J$. Neurosci. 23: 8310-8317.

Lozada, M., Romano, A., and Maldonado, H. 1990. Long-term habituation to a danger stimulus in the crab Chasmagnathus granulatus. Physiol. Behav. 47: 35-41.

Maldonado, H. 2002. Crustaceans as models to investigate memory illustrated by extensive behavioral and physiological studies in Chasmagnathus. In The crustacean nervous system (ed. K. Wiese), pp. 314-327. Springer, Berlin.

McSweeney, F.K. and Swindell, S. 2002. Common processes may contribute to extinction and habituation. J. Gen. Psychol. 129: $364-400$.

Myers, K.M. and Davis, M. 2002. Behavioral and neural analysis of extinction. Neuron 14: 567-584.

Parnas, I., Dudel, J., Parnas, H., and Ravin, R. 1996. Glutamate depresses release by activating non-conventional glutamate receptors at crayfish nerve terminals. Eur. J. Neurosci. 8: 116-126.

Pavlov, I.P. 1927. Conditioned reflexes. Oxford University Press, London.

Pedreira, M.E. and Maldonado, H. 2003. Protein synthesis subserves reconsolidation or extinction depending on reminder duration. Neuron 38: 863-869.

Pedreira, M.E., Dimant, B., Tomsic, D., Quesada-Allue, I.A., and Maldonado, H. 1995. Cycloheximide inhibits long-term habituation and context memory in the crab Chasmagnathus. Pharmacol. Biochem. Behav. 52: 385-395.

Pedreira, M.E., Dimant, B., and Maldonado, H. 1996. Inhibition of protein synthesis and RNA synthesis block context memory and long-term habituation in the crab Chasmagnathus. Pharmacol. Biochem. Behav. 54: 611-617.

Pedreira, M.E., Perez-Cuesta, L.M., and Maldonado, H. 2002. Reactivation and reconsolidation of long-term memory in the crab Chasmagnathus: Protein synthesis requirement and mediation by NMDA-type glutamatergic receptors. J. Neurosci. 32: 8305-8311.

Pedreira, M.E., Perez-Cuesta, L.M., and Maldonado, H. 2004. Mismatch between what is expected and what actually occurs triggers memory reconsolidation or extinction. Learn. Mem. 11: 579-585.
Pereyra, P., Saraco, M., and Maldonado, H. 1999. Decreased response or alternative defensive strategy in escape: Two novel types of long-term memory in the crab Chasmagnathus. J. Comp. Physiol. 184: $301-310$.

Pereyra, P., Gonzalez Portino, E., and Maldonado, H. 2000. Conditioned defensive freezing in the crab is context-specific but not triggered by the context. Neurobiol. Learn. Mem. 74: 119-134.

Pfeiffer-Lynn, C. and Glantz, R. 1991. An arthropod NMDA receptor. Synapse 9: 35-42.

Rescorla, R.A. 2004. Spontaneous recovery. Learn. Mem. 11: 501-509.

Rosenthal, R. and Rosnow, R.L. 1985. Contrasts analysis focused comparisons in the analysis of variance. Cambridge University Press, Cambridge, UK.

Sangha, S., Scheibenstock, A., and Lukowiak, K. 2003a. Reconsolidation of a long-term memory in Lymnaea requires new protein and RNA synthesis and the soma of right pedal dorsal 1. J. Neurosci. 23: 8034-8040.

Sangha, S., Scheibenstock, A., Morrow, R., and Lukowiak, K. 2003b. Extinction requires new RNA and protein synthesis and the soma of the cell right pedal dorsal 1 in Lymnaea stagnalis. J. Neurosci. 23: 9842-9851.

Santini, E., Ge, H., Ren, K., Pena de Ortiz, S., and Quirk, G.J. 2001. Consolidation of fear extinction requires protein synthesis in the medial prefrontal cortex. J. Neurosci. 24: 5704-5710.

Schramm, M. and Dudel, J. 1997. Metabotropic glutamate autoreceptors on nerve terminals of crayfish muscle depress or facilitate release. Neurosci. Lett. 234: 31-34.

Suzuki, A., Josselyn, S.A., Frankland, P.W., Masushige, S., Silva, A.J., and Kida, S. 2004. Memory reconsolidation and extinction have distinct temporal and biochemical signatures. J. Neurosci. 24: 4787-4795.

Szapiro, G., Vianna, M.R., McGaugh, J.L., Medina, J.L., and Izquierdo, I. 2003. The role of NMDA glutamate receptors, PKA, MAPK, and CaMKII in the hippocampus in extinction of consolidated fear. Hippocampus 13: 53-58.

Tomsic, D., Pedreira, M.E., Romano, A., Hermitte, G., and Maldonado, H. 1998. Context-US association as a determinant of long-term habituation in the crab Chasmagnathus. Anim. Learn. Behav. 26: $196-209$.

Troncoso, J. and Maldonado, H. 2002. Two related forms of memory in the crab Chasmagnathus are differentially affected by NMDA receptor antagonists. Pharmacol. Biochem. Behav. 72: 251-265.

Received August 19, 2006; accepted in revised form November 7, 2006. 


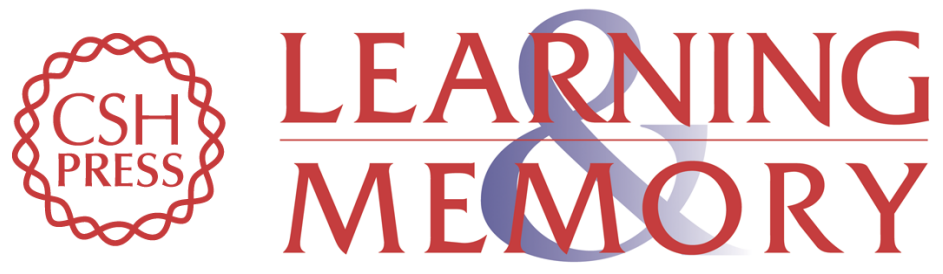

\section{Memory is not extinguished along with CS presentation but within a few seconds after CS-offset}

Luis María Pérez-Cuesta, Yanil Hepp, María Eugenia Pedreira, et al.

Learn. Mem. 2007, 14:

Access the most recent version at doi:10.1101//m.413507

References This article cites 32 articles, 10 of which can be accessed free at: http://learnmem.cshlp.org/content/14/1-2/101.full.html\#ref-list-1

License

Email Alerting Receive free email alerts when new articles cite this article - sign up in the box at the Service top right corner of the article or click here. 